\title{
OBJETIVIDADE, ESTRUTURA E CORRESPONDÊNCIA ENTRE OS CAMPOS DO CONHECIMENTO
}

Marcelo Mari ${ }^{1}$

\section{Resumo}

Mário Pedrosa fez uso da Gestalt menos para a justificação de uma arte de base geométrica, que ressaltasse efeitos das leis da estrutura da visão, e mais para a compreensão da atividade perceptiva e de sua atividade cognoscente. De fato, a adoção da lei primordial - segundo a qual a percepção funda-se em um todo estruturado que não pode ser inferido de suas partes isoladas, sejam elas somadas ou apenas justapostas - revelava o intuito de Pedrosa em encontrar uma unidade da percepção que sustentasse com plausibilidade o conhecimento a partir das relações intrínsecas dos elementos nela estruturados. Por sua vez, esse conhecimento possuía objetividade devido às leis próprias da atividade perceptiva e partia de um acordo entre sujeito e objeto. Objetividade, estrutura e totalidade - ou percepção sincrética global - constituíam a garantia de consonância entre o conhecimento proporcionado pela arte e aquele resultante do desenvolvimento de outros campos do conhecimento.

Palavras-chave: Mário Pedrosa, Gestalt, objetividade e processo cognitivo

Nos anos cinqüenta, a produção intelectual de Mário Pedrosa alcança a unidade entre posicionamento estético e conhecimento social. De um lado, consolida-se o interesse de Pedrosa pela orientação cada vez mais acentuada de continuidade das conquistas efetuadas na arte moderna, ao longo do século XX, na direção tanto da depuração de toda temática nas obras como da autonomia do signo plástico. Essa proposição de autonomia da arte indicava não apenas a negação de uma teoria estética embasada na correspondência simples entre objeto real e objeto representado, que visava estreitar a conexão entre pensamento e realidade pela via de um materialismo vulgar, mas também, a contrapartida social da arte com sua independência crítica frente aos poderes estabelecidos. De outro lado, as potencialidades revolucionárias da arte independente fixavam-se como elemento ativo e transformador no âmago do diagnóstico e das soluções previstas por Pedrosa para o modo de desenvolvimento e de estruturação social contemporâneos.

A aposta de Pedrosa na orientação construtiva da arte moderna era o anverso de sua posição, como intelectual e militante, sobre o novo momento social vivido no Brasil e no mundo. Dessa forma, projeto estético e projeto político coincidiam nos esforços de transformação completa da consciência humana. $\mathrm{O}$ vínculo existente entre arte e política encontrava sua raiz justamente na interpretação comum do processo de conhecimento capaz de elucidar as condições necessárias para uma intervenção efetiva na sociedade. Por certo, a política não tinha precedência sobre a estética, mas a produção artística contribuiria de maneira fundamental para a educação e para a desalienação do homem e, por isso, ocupava um lugar privilegiado no pensamento de Pedrosa. Toda sua reflexão sobre a política não partira do interesse vivaz pela arte moderna, mas esses dois campos aproximam-se principalmente no momento em que nosso intelectual elabora e pormenoriza a afinidade existente entre interpretação do fenômeno artístico pela Gestalt e abordagem da política e da sociedade pela sociologia do conhecimento.

\footnotetext{
${ }^{1}$ Doutoramento em Estética - FFLCH-USP
} 
Ao contrário do que se costuma pensar, as teorias da forma serviram a Mário Pedrosa menos para a justificação de uma arte de base geométrica, que ressaltasse efeitos das leis da estrutura da visão, e mais para a compreensão da atividade perceptiva e de sua finalidade cognoscente. De fato, a adoção da lei primordial da Gestalt - segundo a qual a percepção funda-se em um todo estruturado que não pode ser inferido de suas partes isoladas, sejam elas somadas ou apenas justapostas - revelava o intuito de Pedrosa em encontrar uma unidade da percepção que sustentasse com plausibilidade o conhecimento a partir das relações intrínsecas dos elementos nela estruturados. Por sua vez, esse conhecimento possuía objetividade devido às leis próprias da atividade perceptiva e partia de um acordo entre sujeito e objeto. Objetividade, unidade e totalidade - ou percepção sincrética global - constituíam a garantia de consonância entre o conhecimento proporcionado pela arte e aquele resultante do desenvolvimento de outros campos do conhecimento, e tanto um como outro tinham seu respaldo na experiência direta, no contato entre o sujeito e o objeto.

Mário Pedrosa importava-se sobremaneira não somente com o ideal de unidade dos conhecimentos e com as conseqüências dele para a sociedade, mas em especial com a unidade social. Essa unidade depreendida da noção de estrutura tinha sua origem no pensamento de Pedrosa tanto por causa dos estudos da percepção como pelo respaldo dos estudos de Marx sobre a base da formação social. Sem dúvida, a Gestalttheorie veio fornecer uma nova abordagem sobre as experiências e as observações isoladas a fim de que fosse possível inseri-las em uma totalidade objetiva e lhes devolver significação. Por seu turno, os estudos de Marx lograram ultrapassar a base do conhecimento depositada nas ciências naturais e colocar o homem no centro de todo o processo de produção da realidade. Sem isso, persistiria o impasse da ciência que perdera seus próprios fins. Manter-se-ia o colecionismo sem fim de informações, a falta de uma finalidade significativa capaz de colher e reunir a fragmentação que assolava o conhecimento científico, ou ainda, a separação mecânica entre o conhecimento e o valor dele para o homem. Isso gerava a necessidade - depois do fracasso das explicações teológicas ou metafísicas - de se encontrar um fundamento outro para o conhecimento e para o entendimento de uma unidade nova e plena de sentido sobre o mundo, compatível com o dinamismo e com a complexidade social da vida moderna.

No final do século dezenove e início do século vinte, a ampliação cada vez maior dos horizontes de conhecimentos científicos sem quaisquer relações evidentes entre si e com a sociedade era o principal problema enfrentado pelos intelectuais. Quando encontrou, nos estudos da forma, um indício e um viés de solução para o problema da síntese entre os diversos campos envolvidos na densidade do real, Pedrosa não estava só. Partindo das conquistas de Marx sobre a estruturação social e das descobertas da psicologia sobre o fenômeno perceptivo, o esforço de Pedrosa se somava ao de muitos outros intelectuais, tais como, W. Köhler, Max Weber e Sigmund Freud. Assim como Weber interessou-se vivamente, em "A ética protestante e o espírito do capitalismo", 1904-5, pelo esclarecimento das conjunções que vigoravam na sociedade através da tentativa de formalizar seus aspectos mais importantes, também Freud estudou a origem do psiquismo humano em seus escritos iniciais, cujo exemplo prior é "Totem e tabu", como uma totalidade de relações sociais estabelecidas de uma determinada maneira e não de outra, visando discernir qual seria o aspecto mais importante para o estabelecimento e para a manutenção duradoura da vida do homem em sociedade. 
Como se pode ver, entre esses estudos há uma semelhança não casual de tratamento dado à sociedade como uma totalidade de relações. Se Weber reconheceu na formalização, do que até então era visto apenas como conjunções sociais, a possibilidade de se efetuar relações entre seus elementos, isso foi feito com o intuito de ultrapassar as sérias dificuldades existentes na disputa muito comum entre os diversos conteúdos atribuídos ao sentido último da natureza e da ordem social. Seu empreendimento inscrevia-se na tentativa de dar mais racionalidade e, por conseqüência, mais objetividade ao estudo da sociedade. Aqui, Weber aproximava-se de certa forma das motivações que levaram Freud a interessarse pelo estudo da formação e da organização da sociedade sob o ponto de vista da psicologia. Em "Totem e tabu", 1913, o psicólogo indicou que somente através da repressão dos próprios instintos o homem consegue associar-se com outros homens e formar um agrupamento. $\mathrm{O}$ viés de análise psicológica de Freud encontrava um esteio concreto tanto para a formação da sociedade como para sua manutenção e estava subentendida aí a noção de uma lei seletiva das possibilidades de estruturação social.

O ímpeto daquelas pesquisas era comum e a maioria delas tentou encontrar, cada uma à sua maneira, aquilo que a Psicologia da Forma também forneceu como explicação mais atenta sobre os pressupostos e sobre a essência do processo cognitivo. Essa semelhança entre as pesquisas baseava-se tanto na importância atribuída à descoberta de uma unidade plausível do conhecimento como no recurso à noção de totalidade. Outro ponto que compunha semelhança entre as pesquisas do final do século dezenove e início do século vinte e a pesquisa da Gestalt foi o interesse em definir um princípio ou lei seletiva das possibilidades de estruturação da sociedade. Essa lei estabelecia as condições para que a totalidade estruturada fosse ao fim e ao cabo efetiva e não apenas uma possibilidade de estruturação entre outras. No caso da teoria, ao mesmo tempo antropológica e psicológica, elaborada por Freud em "Totem e tabu", o princípio do incesto consistia regra fundamental para a coesão e a manutenção do agrupamento social. Assim, a teoria de Freud valia-se da semelhança com a lei da melhor organização possível da forma, definida nos estudos da Gestalt ${ }^{2}$.

Se a Gestalttheorie fornecia explicação dos fenômenos psíquicos - e, diga-se de passagem, Pedrosa foi um dos primeiros a estendê-la mais vigorosamente para a análise do campo estético -, com o tempo, percebeu-se a afinidade entre ela e os estudos em diversos campos do conhecimento: sociologia, antropologia, etc. O movimento de ampliação das conquistas da noção de forma coroava a ambicionada recuperação do ideal de unidade dos saberes e permitia, em particular, que se solucionasse o impasse gerado pela dualidade entre conhecimento psicológico e social. Essa dualidade referia-se ao conflito aparente entre

\footnotetext{
${ }^{2}$ Não é por acaso que Wolfgang Köhler aproximava o princípio formal de organização da percepção, através da manifestação do fenômeno de equilíbrio privilegiado da forma, com as descobertas no campo da física. A respeito das idéias de Köhler, Pedrosa comenta: "A organização percepcional não se compara a um chamado urgente à polícia para dominar a desordem. O mesmo princípio formal encontra-se na física, em que suas leis se manifestam em muitos fenômenos, como mostrou Köhler. Compare-se, por exemplo, a certas leis físicas que se regem por um equilíbrio privilegiado, a lei do máximo e do mínimo: uma gota d'água, em suspenso, num líquido de igual densidade, tende para a forma esférica, isto é, ocupa o maior volume e na menor superfície.”, e Pedrosa indica, em Köhler, a ligação entre o conhecimento proporcionado pela percepção e a conduta humana: "“'O conceito da forma pode assim ser aplicado para lá dos limites dos campos sensoriais. De acordo com a definição geral da Gestalt, os processos de aprendizado, de reprodução, do esforço, da atitude emocional, do pensar, da ação etc. podem ser incluídos como tema da Teoria da Forma, desde que não consistam de elementos independentes mas estejam determinados numa situação, como um todo."” PEDROSA, M. "Da natureza afetiva da forma na obra de arte" In Forma e percepção estética. (Org. Otília B. F. Arantes). São Paulo: EDUSP, 1995, p. 116.
} 
indivíduo e sociedade, instância fenomênica do conhecimento e ordenamento social. No primeiro caso, a psicologia tomava o indivíduo e suas faculdades como ponto inicial para a explicação do processo de conhecimento. Ela seguia de perto a tradição filosófica moderna que em geral se apoiou no pensamento individual separado de seu contexto social. No segundo caso, a sociologia não deveria se restringir ao estudo da instauração de acontecimentos sociais específicos sem levar em conta sua lógica interna e o surgimento social do conhecimento.

Muito mais que a oferta de um método formal de organização de elementos, válido tanto para a psicologia como para a sociologia, a noção de forma foi o primeiro resultado sério da análise capaz de priorizar a totalidade das experiências e observações em um dado momento. Dessa precedência das pesquisas efetuadas por Marx e pelos psicólogos da forma surgiu uma avaliação do substrato das teorias epistemológicas, psicológicas ou sociais que adotavam um ponto de vista puramente causal ou de isolamento propositado dos elementos. Seus efeitos fizeram-se sentir em vários campos do conhecimento e se resumiram na avaliação da finalidade significativa dos elementos concernentes à totalidade. Não se tratava apenas de referendar afinidades entre os diversos campos do conhecimento, mas também de esclarecer o que em última instância motivava a escolha de tal ou tal procedimento através da avaliação prioritária das bases em que se fundava todo conhecimento. $\mathrm{Na}$ sociologia e até no plano da ética isso ficou evidente na explicitação da dinâmica entre indivíduo e sociedade, que passava a ser interpretada através do esforço de se integrar os elementos de conduta individual em um contexto estruturado ou configurativo.

$\mathrm{Na}$ época em que as concepções da Teoria da Forma vieram à tona, elas enfrentaram contestações importantes provenientes do objetivismo na psicologia, que considerava o viés da Gestalt como distanciado do método das ciências naturais. Se o objetivismo sofreu influência das ciências e partiu da noção de efetividade cognitiva pela separação entre observador e sistema observado, sua conclusão era negativa com relação à experiência direta. Já que essa dependia do indivíduo e não somente de relações objetivas extrínsecas, conclui-se que a experiência direta restringia-se ao âmbito subjetivo e era desprovida de qualquer valor científico. Ao contrário, para a psicologia da forma, não era exeqüível a separação entre sujeito observador e objeto observado, bem como não temos acesso ao mundo físico e sim ao dos fenômenos. Assim, a formação do conhecimento dava-se na relação efetiva entre sujeito e objeto por via da experiência imediata e direta sobre o mundo fenomênico, onde as leis da percepção eram a garantia de objetividade da percepção e, por conseguinte, da observação científica.

$\mathrm{O}$ fato do conhecimento sobre o mundo ser resultado de um processo em que o sujeito encontra-se intrinsecamente envolvido não invalida a experiência objetiva que esse mesmo sujeito tem do mundo e que partilha com os outros. Segue-se disso que, a noção de objetividade refere-se ao mundo experimentado direta e imediatamente pelo sujeito. Ela permite que se dê unidade aos vários campos do conhecimento pelo procedimento de análise que lhes é comum e pela circunscrição das relações estabelecidas entre eles na totalidade da experiência cognitiva. Essa unidade torna-se quesito para que a noção de objetividade não incida nos prejuízos ontológicos do objetivismo, causados pela separação entre pensamento e mundo e pelo suposto acesso direto às essências do mundo. $\mathrm{O}$ pensamento não organiza um conjunto de experiências atomizadas ou de observações isoladas em uma fórmula ideal ou em uma unidade ideada, mas constituí-se na relação inescusável com o mundo. Em resumo, não há nem separação entre um suposto 
pensamento ordenador e o caos do mundo nem uma aproximação privilegiada dos campos de conhecimento, sejam eles quais forem, com a essência ou verdade das coisas.

É preciso notar que a noção de forma promoveu uma mudança substantiva no entendimento dos fenômenos psíquicos e sociais. Em fins do século dezenove, vigia na sociologia a comparação da sociedade com um ser vivo. Essa tendência foi representada de modo emblemático por Auguste Comte e por Herbert Spencer. Ambos acreditavam que a sociedade deveria ser analisada por um método equivalente ao das Ciências Naturais. Isso porque, havia uma identificação entre razão e natureza que justificava o entendimento da sociedade como um organismo e estabelecia para ela uma teleologia positiva. Para Spencer, por exemplo, o organicismo confirmava a insuficiência de qualquer análise ou intervenção planejada sobre a sociedade, já que o organismo social perdia vida e que deveria ser deixado livre em seu desenvolvimento. Essas idéias sobre a sociedade justificavam a doutrina política do Laissez Faire, Laissez Passé. Em suma, a sociedade participava de um processo evolutivo, o que permitia ancorá-la - mais do que por simples analogia - à teoria das espécies de Darwin.

A principal falha dessas teorias sociais consistia na omissão evidente dada ao fator humano, às tensões e à totalidade do processo social. Esses pontos de reflexão favoreceram a legitimidade das pesquisas da forma no campo da sociologia. Com os estudos iniciais da psicologia da forma, o conceito de organismo foi logo substituído pelo de configuração, que levava em conta dois aspectos importantes: primeiro, a constante de ordenação dos sistemas não pode ser dada pelo cálculo da importância de cada elemento em separado do conjunto; segundo, todo sistema organiza-se através do princípio de escolha da melhor ordenação possível. Mesmo que pareça haver semelhança entre a noção de organismo e de configuração, sua diferença fundamental reside no fato de que a corrente positivista fixava uma explicação naturalista do estabelecimento da ordem social ao passo que a corrente formalista vinculava-se menos ao estudo do conteúdo e mais ao das relações sociais. Assim, a proposição positivista orgânica afirmava que não havia ordem dos diversos componentes sociais senão aquela gerada pela natureza e que a variação da organização social referia-se ao conteúdo específico de cada sociedade.

Da mesma forma que as teorias modernas de Weber, de Freud e da Gestalttheorie, também a teoria organicista ou positivista perseguiu um ideal de unidade dos saberes, mas sua principal diferença frente àqueles intelectuais foi o fundamento último e natural dado ao processo de conhecimento. A partir desse fundamento - resultante da importância atribuída às descobertas realizadas no campo das ciências -, deduzia-se uma escala valorativa e positiva do progresso ou evolução humana. Esse aspecto da teoria positivista é ressaltado ainda mais na transferência da discussão sobre o processo de conhecimento para a abordagem da sociedade. Não se partia da idéia de uma estrutura de relações comuns às diversas sociedades formadas, mas de uma diferenciação hierárquica das sociedades consoante com uma escala civilizacional positiva ou evolutiva. Por sua vez, sem precisar recorrer a um fundamento último da noção de estrutura e partindo de pesquisas em psicologia, os teóricos da Gestalt tiveram seu conceito - sobre uma tendência privilegiada entre as formas - estendido para diversos campos do conhecimento.

Para além dos limites epistemológicos da noção de estrutura ${ }^{3}$ pode-se apontar duas maneiras operativas de compreendê-la, a saber: uma, que a considera como forma

\footnotetext{
3 Ver KOFFKA, K. Princípios de psicologia da Gestalt. São Paulo: Editora Cultrix \& EDUSP, 1975, pp. 3334. Nessa introdução à psicologia da forma, Kurt Koffka discute a impossibilidade de generalização da categoria "gestalt". Segundo o autor, tratar-se-ia de um preconceito metafísico ou de um equívoco ontológico
} 
invariante e universalizável; outra, que leva em conta as condições dadas para a consolidação de uma determinada forma em detrimento das outras possíveis. Essa diferença entre elas marca a passagem de uma concepção mais próxima do sentido original de estrutura dinâmica defendido pelas pesquisas da Gestalt e outras concepções. Pode-se dizer que, a distinção torna-se mais evidente na medida em que a concepção operativa encontra seu objeto. No que concerne aos estudos sobre a sociedade, verifica-se uma homologia estabelecida para as duas maneiras operativas de se abordar a estrutura: a primeira abordagem interessa-se mais pela estrutura antropológica generalizável e menos pelas condições específicas de cada sociedade; a segunda abordagem mantém a noção de estrutura generalizável, mas mantém sua base nas condições sociais e psíquicas indispensáveis para o surgimento de uma determinada estrutura da sociedade.

A explanação da noção de estrutura encontra lugar na tese de Mário Pedrosa, "Da natureza afetiva da forma na obra de arte", no momento em que ele apontou no exórdio a percepção como origem de todo conhecimento ao longo da história humana. À primeira vista podia parecer que com isso se legitimasse apenas uma noção de estrutura subsistente ao tempo, baseada na validade permanente das leis que governam a percepção. Contudo, se se observa com atenção o desenvolvimento da argumentação de Pedrosa - na parte da tese em que estão em discussão os problemas da relação entre forma e significação bem como na parte da conclusão ${ }^{4}$-, tem-se a certeza de que não havia exclusividade de interesse pela noção de uma estrutura antropológica subjacente a todas as sociedades, pois são aludidos os fatores condicionantes que interditam ou obliteram a percepção. Os fatores psíquicos e os sociais revelavam o vínculo entre estrutura do conhecimento e processo histórico do conhecimento, suscetível de desvios e inflexões. Portanto, as leis invariáveis da percepção importavam com efetividade tanto quanto as condições históricas responsáveis pelo decréscimo das capacidades perceptivas em relação ao aumento do conhecimento intelectualista. No estudo sobre a sociedade, chegava-se à mesma via.

entender a Gestalt como um princípio correspondente à essência do universo e que seus elementos in limine formassem uma só e única Gestalt.

${ }^{4}$ Cf. PEDROSA, M. "Da natureza afetiva da forma na obra de arte" In Forma e percepção estética. (Org. Otília B. F. Arantes). São Paulo: EDUSP, 1995, pp. 140-143 e pp. 172-176. 